\title{
POLYMYOGRAPHIC STUDIES OF SOME INVOLUNTARY MOVEMENTS IN SUBACUTE SCLEROSING PAN-ENCEPHALITIS
}

\author{
BY \\ G. PAMPIGLIONE \\ From the Department of Electroencephalography and Clinical Neurophysiology, \\ The Hospital for Sick Children, Great Ormond Street, London
}

(RECEIVED FOR PUBLICATION JULY 7, 1964)

Subacute sclerosing pan-encephalitis is an insidious illness and is probably less rare than it appears from some reports (Lancet, 1963). Nearly 100 cases have been verified histologically in one laboratory alone (L. van Bogaert, personal communication, 1964), though probably the material was collected from many sources. The name of this condition (and its few variants) is derived directly from the histopathological findings in the verified cases. Since the demonstration of particular EEG features during early phases of the illness in well-documented cases (Radermecker, 1949: Cobb and Hill, 1950: Pampiglione and Martin, 1953; Cobb, 1963, amongst others), it has been possible to suggest the diagnosis even in the absence of the characteristic involuntary movements. When the involuntary movements make their appearance, they seem to bear a definite time relation to the periodic EEG features, as described by various authors (see review of early literature in Radermecker, 1956). In another paper in this journal Sandifer and co-workers describe the main aspects of the involuntary movements as seen by the clinician (Metz, Gregoriou, and Sandifer, 1964).

This contribution will be limited to the polymyographic observations made on 12 children with subacute sclerosing pan-encephalitis, referred to this hospital department since 1957. The diagnosis was eventually proven histologically in 10 children while in the remaining 2 the paretic Lange curve, the periodic movements, and the EEG features were considered sufficient diagnostic evidence. Though these involuntary movements are usually called 'myoclonic' by many authors, the purpose of this paper is to show the complex relation of the electrical events underlying the visible motor phenomenon in various groups of muscles.

\section{Material and Method}

The 12 patients studied are part of the group reported by Metz et al. (1964). Both EEG and polyelectromyographic (poly EMG) studies were made with mobile or portable 8-channel apparatus (Offner Type D and T), and often patients were studied in their own beds. Silver, silver-chloride disc electrodes were employed, stuck to the skin with collodion, the contact being made through a saline jelly. The electrodes were placed on the scalp to measurements from bony landmarks, according to a method used in several EEG laboratories in Europe (Pampiglione, 1956). The contact resistance was lowered to less than 5 KOhms. A similar technique was employed for the polyelectromyography with surface electrodes to record the activity of both agonist and antagonist groups of muscles in several limbs (Pampiglione, 1959, 1961). The paper speed of the recorder varied from $6 \mathrm{~cm}$./ $\mathrm{sec}$. to 1.5 or even $0.6 \mathrm{~cm}$. $/ \mathrm{sec}$. according to the various types of phenomena to be illustrated. The amplification was of the order of 10 to $\mathbf{4 0}$ microvolts per millimetre pen deflection for both the EEG and the poly EMG, but the time constant was kept long (either 0.3 or 1 second) for the EEG, and short (either 0.1 or 0.03 second) for the poly EMG. No HF filters were added and the frequency response was linear within $10^{\circ}$ up to $60 \mathrm{c} / \mathrm{s}$ decreasing gradually thereafter. The poly EMG technique was standardized to make it applicable even to extremely disabled patients. Attempts were always made to record while the patient was at rest, during some voluntary movements, during some passive movements, in response to unexpected simple stimuli, and, whenever possible, while particular postures were voluntarily maintained for periods of half to one minute. When the characteristic EEG features had been seen, records from the muscles were taken whether or not visible involuntary movements could be observed in the patient's limbs or body.

\section{Results and Discussion}

The EEGs of all the 12 patients showed repetitive complex changes at intervals of 4 to 20 seconds. 
The periodic appearance of groups of muscle action potentials while the patients were resting occurred in all 9 with recognizable involuntary movements. These were seen about the time of the appearance of the repetitive complex EEG changes. Comparable electromyographic changes could be detected also in the other 3 patients, who had not yet developed recognizable periodic involuntary movements while resting, but in whom a voluntary steady posture was temporarily altered during the periodic EEG changes. A great variety of EMG events was seen even in the same patient, if studied over a period of many minutes or at intervals of days, weeks, or months, though the periodicity of the EEG and motor phenomena remained fairly constant. In general the movements were not abolished by sleep but their EMG pattern was considerably modified.

It was the exception to see single isolated muscle action potentials, even when clinically the involuntary movements were very brief. Usually the muscle action potentials appeared in groups often lasting more than one-quarter of a second. A common phenomenon, particularly in the early phases of the disease, was a complex sequence of fluctuating activity in the EMG from various groups of muscles during each involuntary movement. After an initial group of muscle action potentials, occurring about the beginning of the repetitive complex wave form in the EEG, there was either a period of complete electrical 'silence' or a period of marked diminution in muscle action potentials, coinciding usually with the large slowest wave in the EEG complex. Then the muscle action potentials would reappear, often in brief multiple irregular groups. It was often possible, with the guide of the poly EMG, to recognize clinically a minimal complex movement of the limbs involving a temporary relaxation which coincided with the relative electrical 'silence' in the poly EMG. In a study of 23 cases of subacute sclerosing pan-encephalitis collected in Holland by Hamoen, Herngreen, Storm van Leeuwen, and Magnus (1956) as well as in the recent paper by Tibbles, Donohue, Kofman, and Prichard (1964) the occurrence of brief periods of 'loss of tone' is mentioned and this phenomenon had already been considered by Radermecker (1956) amongst others, but none of these authors had carried out polymyographic studies. The phenomenon of periodic involuntary 'relaxation', as detectable with the poly EMG monitoring, has been a common finding in our

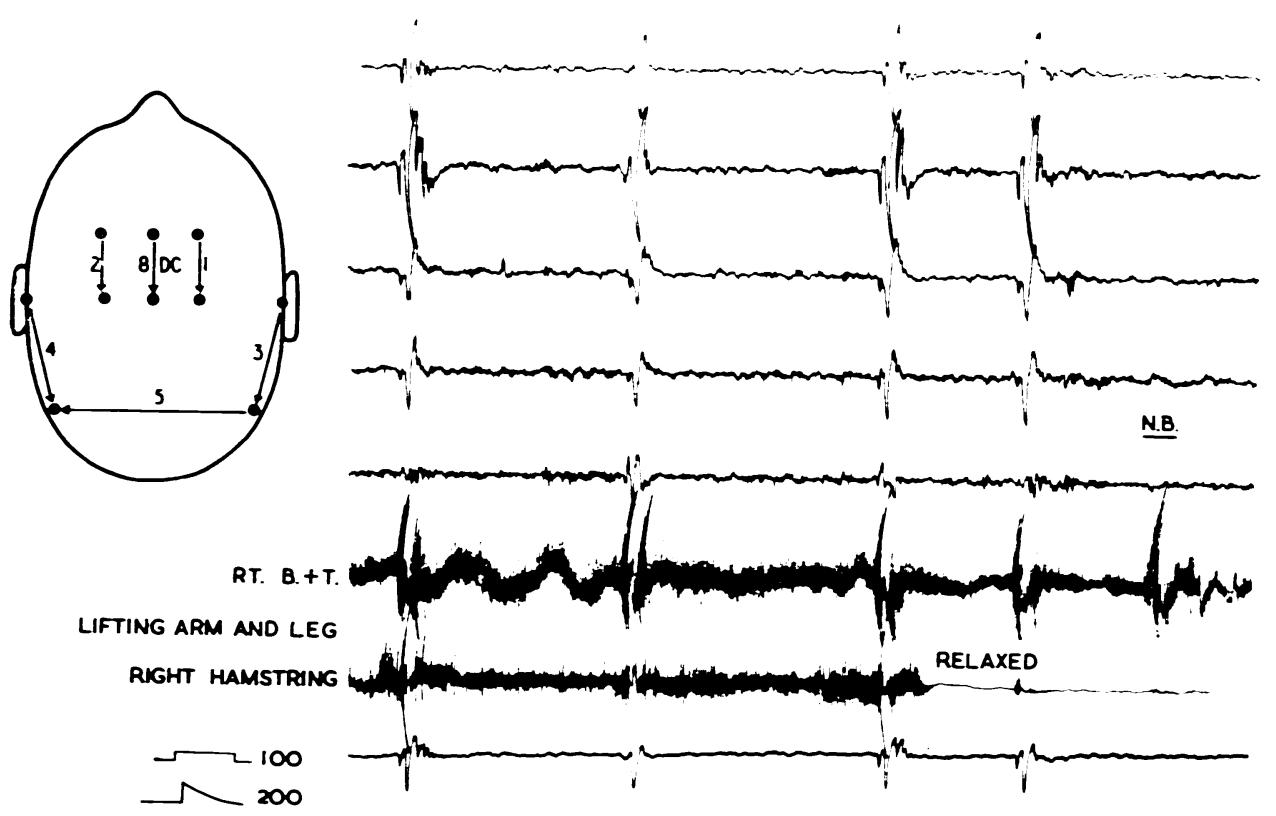

FIG. 1.-This boy of 11 showed periodic involuntary movements at intervals of 6 to 12 seconds on August 27,1957 . The first five channels record the EEG as in the diagram on the left (time constant of 0.3 second). The eighth channel records also the EEG but the amplification is reduced and the record is DC. Channel 6 and 7 record the myogram (surface electrodes) during a slow voluntary movement upon which the involuntary movements intrude. When the patient rested his leg (see indication) the superimposed periodic myographic phenomenon in the leg changed considerably, while the grouping of action potentials in the arm changed to a much lesser extent.

On one occasion only a group of muscle action potentials accompanying a visible jerk occurred without any recognizable EEG change. 


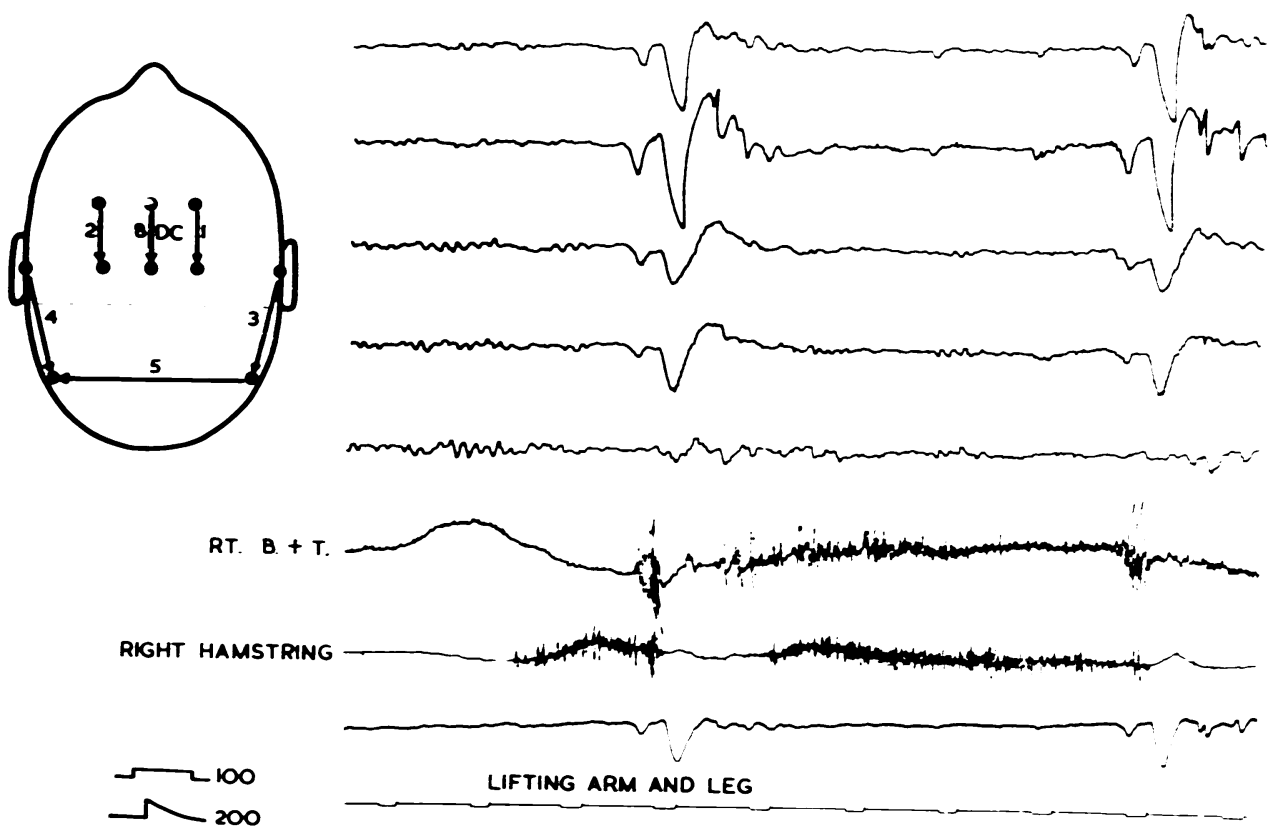

FIG. 2.-The same boy as Fig. 1 with the same montage (August 27, 1957). Note the period of relative electrical 'silence' after the initial group of muscle action potentials coinciding with the appearance of the larger slow elements in the EEG.

material. This was easily demonstrable when the patient was able to maintain a posture involving moderate though steady activity of several groups of muscles (Figs. 1 and 2). The transitory disappearance of muscle action potentials often occurred to a slightly different extent, either in the agonist or in the antagonist muscles in one or more limbs (Fig. 4) during a voluntary effort. The duration of the period of electrical 'silence' tended to vary a little from one episode to another in the same patient for no easily recognizable cause: and such periodic involuntary relaxation might differ between one and the other group of muscles (Fig. 2). The size and grouping of muscle action potentials during the 'active' phase, however, seemed to vary much more than the duration of the 'relaxation' or 'silent' phase, not only at rest but also during active movements, or in response to stimuli and during sleep. On occasions either during the waking resting state or during sleep, only an initial group of muscle action potentials was seen, followed by a relative 'silence' without the reappearance of a second group of muscle action potentials (Fig. 3). Often the involuntary movements at rest (as well as the concomitant 'active' EMG phenomena) were limited to one limb and sometimes confined only to one group of muscles (Fig. 4A). However, during voluntary effort in the same patients the 'relaxation' or 'silent' phase would become apparent in many more groups of muscles, even if some were slightly more affected than others (Fig. 4B and C).

These phenomena could be influenced only to a limited extent by the direction and range of a voluntary movement when studied over a period of several minutes. However, on re-examining the the patient on another day a different pattern of abnormal co-ordination might be seen. The extent and duration of both 'positive' and 'negative' EMG phenomena in different muscles during each spasm could vary a great deal (see Fig. 5A and B) and on different occasions each phenomenon might have a particular sequence in each group of muscles examined.

The electrical activity of the muscles in the present study has been used to detect changes probably occurring at central level and at present we may only note and keep a record of phenomena that we do not fully understand. Our total ignorance of the central phenomena underlying the electrical and motor events described should not discourage us from collecting data upon complex patterns of abnormal motor co-ordination peculiar to this illness. It seems probable that only by keeping permanent records of patterns of co-ordination of motor activity in well- 

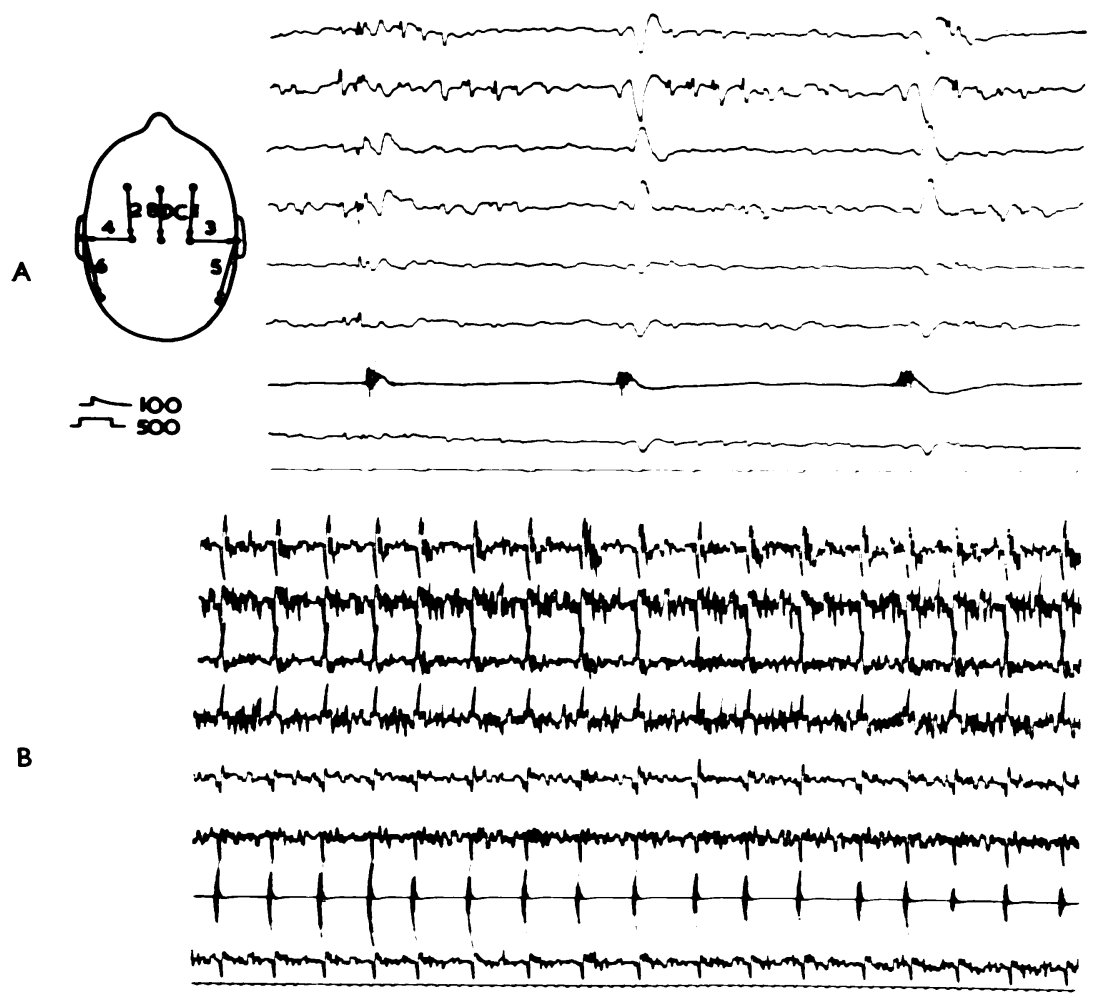

FIG. 3.- The same patient as in Figs. 1 and 2. A. The record was taken 9 days later (September 5, 1957). The muscle action potentials seen at rest from the right biceps have changed (see channel 7). The periodicity is fairly regular at 5- to 6-second intervals. B. Taken 4 days later (September 9). the child was asleep after administration of quinal-barbitone. The periodicity was very regular at about 6-second intervals, but the amplitude of the groups of muscle action potentials tended to vary without, however, any recognizable change in the patient's clinical state.

documented cases, might we be able to reconstruct, in time, the jigsaw puzzle of the peculiar progressive disruption of skills that occurs during the evolution of this usually fatal illness, and possibly also of other progressive diseases. Why should the involuntary movements that persisted with clockwork regularity for months, disappear altogether in some patients? Why should the peculiar EEG features during the florid phase often disappear either during a partial recovery phase, or sometimes in the terminal phases? Why should the EMG events be so complex and often variable during some apparently stereotyped and repetitive motor phenomena? What are the healthy and the diseased mechanisms of the central nervous system that underly the periodic EEG and motor phenomena? At present it can only be said that the use of the term 'myoclonus' to describe even the briefest of the jerks seen in our cases would be misleadingly simple. A periodic 'complex spasm' usually combined with a phase of motor 'relaxation' lasting even half a second or more seemed the most common feature in the early phases of subacute sclerosing pan-encephalitis studied in this series of patients.

\section{Summary}

The involuntary movements that recur at fairly regular intervals during the course of subacute sclerosing encephalitis have been studied in 12 children with a poly-electromyographic technique described elsewhere. It has been found that the involuntary movements, both in early and later phases, consist of complex spasms, usually combined with a phase of motor 'relaxation'. The complexity of the apparently stereotyped involuntary movement may vary considerably over a period if the electrical events occurring in various muscles at the same time are compared.

It is a pleasure to thank my colleagues who referred their patients for neurophysiological studies and in particular, Dr. Paul Sandifer. I am indebted to my indefatigable EEG recordists, Miss Jane Chaloner and 


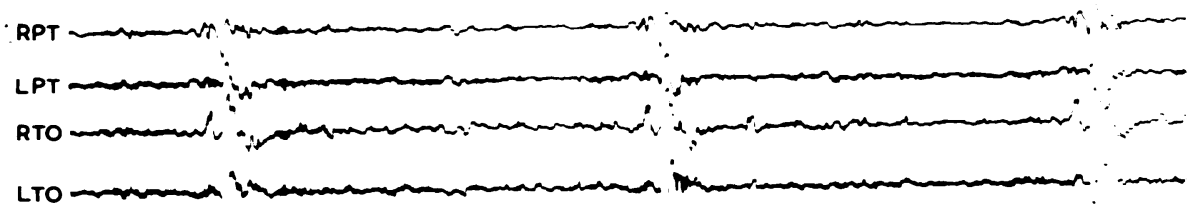

A

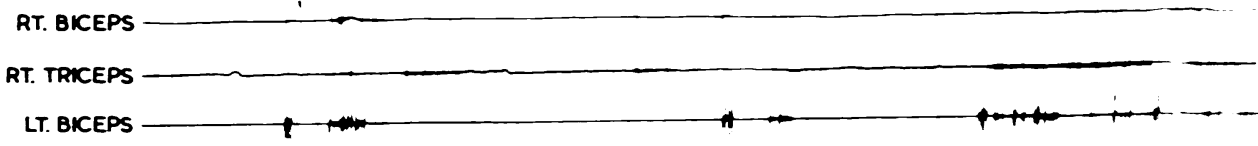

LT. TRKEPS
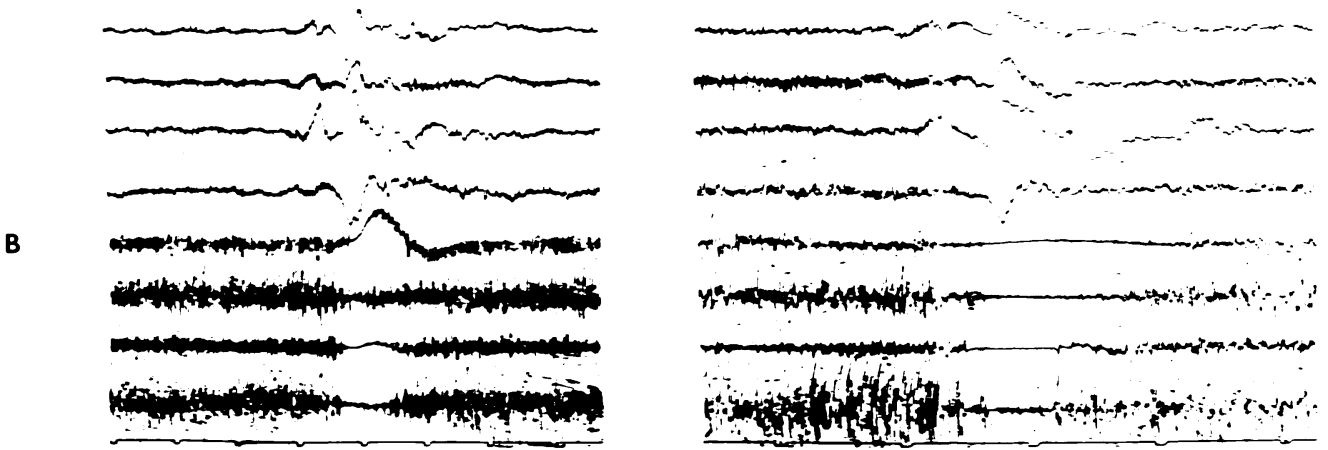

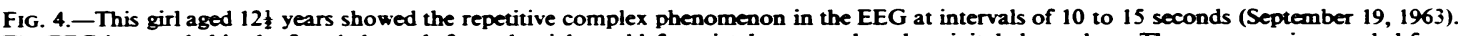
The EEG is recorded in the first 4 channels from the right and left parietal, temporal, and occipital electrodes. The myogram is recorded from both right and left biceps and triceps. (A) illustrates the pattern when the patient was at rest, and (B and C) when carrying out a slow voluntary movement.

At rest, the positive electrical phenomena from the right biceps were minimal, but a period of relative electrical 'silence' was always present at the time of the complex EEG phenomenon. Though no movement was seen in the right arm, a very low amplitude group of muscle action potentials appeared at the beginning and occasionally also after the end of the EEG phenomenon. In the left arm the EMG changes were more marked, there appearing, in the biceps, groups of large muscle action potentials followed by a period of 'silence' lasting nearly a second and then more irregular grouping of muscle action potentials. But in the triceps (which the patient was unable to relax fully) there was an obvious period of electrical 'silence' on each occasion, while the 'positive' phenomena were minimal.

When the patient was carrying out a voluntary movement (holding her arms outstretched as in the bottom half of the illustration), there was no longer a grouping of muscle action potentials at the beginning of the complex EEG phenomenon. The most constant feature was the total disappearance of muscle action potentials from the biceps on both sides and a gross diminution in muscle action potentials from the triceps on both sides for a period of about half a second.

Mrs. Rita Cornish, and also to Mr. Derek Martin. Part of this work was supported by a grant of The Polio Research Fund.

\section{RefERENCES}

Cobb, W. A. (1963). Subacute encephalitis. In Proceedings of the Marseilles Colloquia, 1963. Epilepsia (Amst.). To be published. and Hill, D. (1950). Electroencephalogram in subacute progressive encephalitis. Brain, 73, 392.

Hamoen, A. M., Herngreen, H., Storm van Leeuwen, W., and Magnus, O. (1956). Encéphalite subaigué progressive." Constatations cliniques et électroencephalographique dans 23 cas. Rev. neurol., 94, 109.

Lancet (1963). Annotation. Subacute inclusion encephalitis. 1,153

Metz, H., Gregoriou, M., and Sandifer, P. H. (1964). Subacute sclerosing pan-encephalitis. A review of 17 cases with special reference to clinical diagnostic criteria. Arch. Dis. Childh., 39, 554.
Pampiglione, G. (1956) Some anatomical considerations upon electrode placement in routine EEG. Proc. electrophysiol. Technol. Ass., $7,20$.

- (1959). Polymyographic studies of voluntary and involuntary movements (First National Spastics Society Study Group Oxford, Sept. 1958). Cerebr. Palsy Bull., 1, no. 7, p. 10.

(1961). Polymyographic studies before and after neuro-surgical operations. (Second National Spastics Society Study Group. Oxford. Sept. 1960). Child Neurology and Cerebral Palsy [Little Club Clinics in Developmental Medicine No. 2], p. 27. , and Martin, F. (1953). Périodicité de quelques phénomènes cérébraux. (Étude electroencéphalographique). Schweiz Arch. Neurol. Psychiat. 71, 276.

Radermecker, J. (1949). Aspects électroencéphalographiques dans trois cas d'encéphalite subaigué. Acta neurol. belg., 49, 222.

- (1956). Systématique et Electroencéphalographie des Encéphalites et Encéphalopathies. Masson, Paris.

Tibbles, J. A. R., Donohue, W. L., Kofman, O., and Prichard, J. S. (1964). Subacute inclusion encephalitis. A clinical and pathological review. Canad. med. Ass. J., 90, 401. 

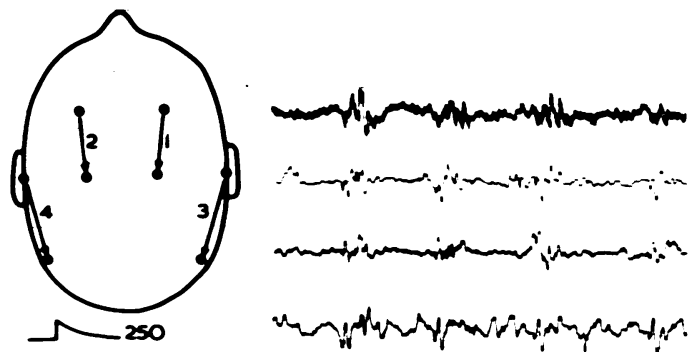

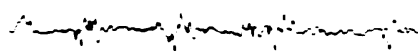

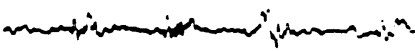

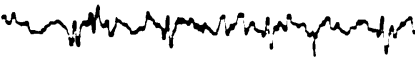

RT. BXEPS

A

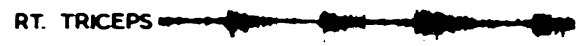

RT. TIB. ANT. -

RT. GASTROCN.

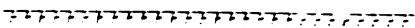

FKG. 5. This child was studied at a much more advanced phase of the disease. A. The first four channets recorded the EEG with a considerably reduced amplification, while the other channels recorded the electromyograms. In the various muscles examined, the duration of the periods of activity during each spasm is not similar.

B. The grouping of the muscle action potentials changed during attempts at voluntary movement. A short period of diminished activity was seen in the muscles of the arm, but this phenomenon was not obvious in the muscles of the leg. 